\title{
Timber supply analysis: An industrial model from British Columbia
}

\author{
by David M. Carson, R.P.F.
}

Modelling processes are being introduced to improve the integration of various resource management objectives. As a mechanism to protect non-timber values, the BC Ministry of Forests has implemented forest cover constraints which place area-based maximum and minimum limits on harvest disturbance and old growth retention, respectively, within forest management zones. Timberline Forest Inventory Consultants has developed a proprietary model that explicitly deals with resource demands such as visual quality objectives, habitat protection measures, and water quality protection guidelines. The model uses a pseudo-geographic inventory to simulate the intent of forest cover constraints on harvesting. A variable degree of spatial resolution is available depending on inventory formulation and management zone definition.

Key words: British Columbia, integrated resource management, modelling, forest cover constraints, spatial resolution
Les processus de modélisation sont de plus en plus utilisés dans le but d'améliorer l'intégration des différents objectifs d'aménagement des ressources. Le ministère des Forêts de la C.-B. a mis en place à titre de mécanisme de protection des valeurs non ligneuses, des contraintes reliées au couvert forèstier qui déterminent des limites maximales et minimales basées sur la surface respectivement pour les perturbations suite à la récolte et pour la préservation des vieilles forêts dans les zones d'aménagement forestier. Timberline Forest Inventory Consultants a élaboré un modèle qu'il détient sous une marque de commerce et qui traite explicitement des demandes associées aux ressources tels les objectifs de qualité visuelle, les mesures de protection des habitats, ainsi que les directives de protection de la qualité de l'eau. Le modèle utilise un inventaire pseudo-géographique pour simuler l'impact des contraintes associées au couvert forestier sur la récolte. Un niveau variable de résolution spatiale est disponible en fonction du type d'inventaire et de la définition de la zone d'aménagement.

Mots clés: Colombie-Britannique, aménagement intégré des ressources, modélisation, contraintes du couvert forestier, résolution spatiale

\section{Introduction}

Within the Province of British Columbia there are 43 million ha of forest land managed within 36 Timber Supply Areas and 34 Tree Farm Licenses. Analysis of timber supply on this land base is mandated to reflect the integrated management of all resources. In BC, new timber supply modelling processes are improving our ability to address integrated resource management objectives. The British Columbia Ministry of Forests $(\mathrm{MoF})$ has adopted constraints on forest cover as a mechanism to protect non-timber values.

Presented in this paper is an approach to modelling and a proprietary model developed to explicitly handle forest cover constraints. The current state of the model, its functions and characteristics, are the result of experience gained through many timber supply analysis projects covering a large proportion of British Columbia. These analyses were undertaken by several analysts during the past few years. The result has truly been a team accomplishment.

\section{BC Implementation of Forest Cover Constraints}

During the past decade, and all across British Columbia, there has been a growing incongruity between harvest levels based on timber supply analysis, and harvest levels for which cutting permits could be secured. Operational limitations on harvesting, such as adjacent green-up, visual landscape harvest controls, harvest exclusions from domestic watersheds and other non-timber resource management factors, have not been reflected in the allowable cut determination.

Timberline Forest Inventory Consultants, Suite 210, 1207 Douglas Street, Victoria, British Columbia, Canada V8W 2E7.Mr. Carson is a Forester and Resource Analyst with Timberline Forest Inventory Consultants in Victoria, British Columbia.
In order to address this, the Ministry of Forests introduced forest cover constraints as a proxy for the effects of spatial constraints and geographic relationships on harvesting. "Spatial" refers to issues of relative location such as adjacency. With the term geographic, we refer to the "lay of the land" and issues such as logical groupings. Forest cover constraints are used to: 1) limit the area to be harvested, and 2) set minimum levels of older aged stands which must be retained. Implementation of constraints has been within five major themes in integrated resource management:

- Visual quality and recreation

- Wildlife habitat

- Watershed protection

- Old growth retention and

- Maintenance of biodiversity.

\section{Visual Quality and Recreation}

The BC Ministry of Forests Recreation Branch produced a guideline document for addressing recreation resources in timber supply analysis (BC MoF Recreation Branch 1993). Recreation resources and wilderness areas in which no harvesting will be allowed are handled through area removals. In the case of visual landscape resources, constraints on harvest are used because specific area reductions do not address visual characteristics of a forest landscape. Modelling to maintain a certain visual quality involves a maximum percent harvest and a time interval until areas harvested are re-established, or visually greenedup. Five visual quality objectives were established and defined as (BC Ministry of Forests Recreation Branch 1991):

- Preservation: No alterations to the natural landscape

- Retention: Alterations are not easy to see

- Partial Retention: Alterations are visible but not conspicuous

- Modification: Alterations are easily seen but do not overwhelm

- Maximum Modification: Alterations dominate the landscape. 
Data organization for modelling traditionally involved a "netting-down" process which was used to identify the portion of the land base available for harvest. This "net area", however, is an incomplete description of the landscape for any purpose other than harvesting. Within the landscape there are the following components:

- Net operable area which contributes to harvesting

- Non-forest/non-productive forest areas

- Productive land with non-commercial vegetation cover

- Inoperable productive land with forest cover

- Productive forest with non-merchantable forest and/or low productivity sites

- Environmentally sensitive areas to which timber harvesting access is not appropriate.

Any of these categories may contribute to the visual scene, to biodiversity, or to wildlife habitat, or they may provide opportunities for improved forest production through silviculture. Of particular concern are the green areas "rejected" in the traditional net-down approach, but intimately mixed with the harvesting land base. The maximum percent harvest permitted for each of the visual quality objectives is set to reflect current management and the state of the particular forest with regard to landscape sensitivity and existing visual condition. All green areas of the land base, even those not available for harvest (inoperable), are factored into the calculation of cover constraints to reflect their impact on the visual landscape. The impact of these green-inoperable areas is dependent on their spatial arrangement. Current practice, however, is to remove these areas; their existence and dispersal is considered only in formulation of the constraints.

\section{Wildlife Habitat}

Wildlife habitat objectives can be especially difficult. They are often ill-defined or involve stand attributes not usually available for analysis. Habitat requirements are often based on thermal cover which usually involves stand retention limits set at a much younger age than constraints for old growth. Constraints for habitat protection are best handled with a second and overlapping retention forest cover class.

\section{Watershed Protection}

Watershed protection is addressed using disturbance constraints with green-up heights based on hydrologic recovery, and maximum harvest values based on provincial or regional guidelines for watershed management.

\section{Old Growth}

Old growth retention is usually handled using a minimum proportion of the forest land required to be in a state of old growth. Old growth is simply defined by age.

\section{Maintenance of Biodiversity}

Biodiversity is handled using old growth retention constraints. The current approach in BC is to retain certain proportions of biogeoclimatic zones in old growth to preserve biodiversity. This approach may require that the management zones defined for modelling be based on the biogeoclimatic system.

Visual quality, old growth, wildlife, watershed protection, biodiversity - frequently more than one of these themes are pursued at once on the same land base. Each may have different, even conflicting, forest cover requirements. Sometimes
Table 1. Strathcona Timber Supply Area forest cover constraints

\begin{tabular}{lrrrr}
\hline & & \multicolumn{3}{c}{ Disturbance constraints } \\
\cline { 5 - 6 } & $\begin{array}{c}\text { Percent } \\
\text { of TSA }\end{array}$ & $\begin{array}{c}\text { Maximum } \\
\text { area }\end{array}$ & $\begin{array}{c}\text { Age } \\
\text { disturbance } \\
\text { Age }\end{array}$ & $\begin{array}{c}\text { Implied } \\
\text { harvest } \\
\text { rotation }\end{array}$ \\
\hline Kyuquot timber supply block & & & & \\
Conventional harvesting methods & 32 & 14 & 25 & 56 \\
Retention VQO & 4 & 20 & 5 & 400 \\
Partial retention VQO & 12 & 20 & 11 & 182 \\
Modification VQO & 3 & 21 & 27 & 78 \\
Non-conventional harvesting & 2 & 15 & 25 & 60 \\
Non-conv. retention VQO & 0 & 21 & 42 & 50 \\
Non-conv. partial retention VQO & 0 & 19 & 42 & 45 \\
Non-conv. modification VQO & 0 & - & - & - \\
& & & & \\
Sayward/Loughborough timber supply blocks & & & \\
Conventional harvesting methods & 28 & 13 & 25 & 52 \\
Retention VQO & 4 & 18 & 5 & 360 \\
Partial retention VQO & 11 & 18 & 11 & 163 \\
Modification VQO & 2 & 18 & 27 & 67 \\
Deer habitat & 0 & 12 & 25 & 48 \\
Non-conventional harvesting & 1 & 14 & 25 & 56 \\
Non-conv. retention VQO & 0 & 18 & 14 & 121 \\
Non-conv. partial retention VQO & 0 & 20 & 33 & 61 \\
Non-conv. modification VQO & 0 & 20 & 69 & 29 \\
\hline
\end{tabular}

${ }^{\mathrm{I} V Q O}$, visual quality objective.

apparent conflicts can be resolved, or the net burden of constraints lightened, if there is in fact spatial or temporal separation between the areas on which the constraints apply.

\section{Impact on Harvest Levels}

The magnitude of the impacts of forest cover constraints can be illustrated by an example from the Strathcona Timber Supply Area (TSA) on the BC coast (Timberline Forest Inventory Consultants 1995a). Zonation in the Strathcona TSA as defined by the MoF was based on supply block, visual quality objectives and conventional vs. helicopter logging areas. Forest cover constraints used for the Strathcona are provided (Table 1).

This particular TSA has only about $63 \%$ of the productive forest available for harvesting: the remaining $37 \%$ is either unmerchantable, inoperable or removed for environmental sensitivity. For this reason the need for retention constraints is low and only disturbance constraints were used (one exception for deer habitat is not shown in the table).

Implied harvest rotation figures (Table 1), are used as a way of comparing the relative impact of forest cover constraints, incorporating both the impact of the minimum age and minimum percentage parameters. They are a calculation based on normalizing the forest within the constraint and do not reflect forest level analysis results. Minimum harvest ages (about 80 to 120 years) are not replaced by these figures.

The harvest schedule for the Strathcona TSA is presented (Fig. 1). The base case included forest cover constraints. Results with no constraints are shown as incremental to the base case. The Strathcona constraints are not severe when compared to other timber supply areas. However, application of these forest cover constraints results in a $15 \%$ reduction in harvest level in the first decade and an average of $22 \%$ over a century.

\section{CASH-FM}

The Timberline model is called CASH-FM, an acronym for Continuous Area Simulation of Harvesting and Forest Management (Timberline Forest Inventory Consultants 1995b). 


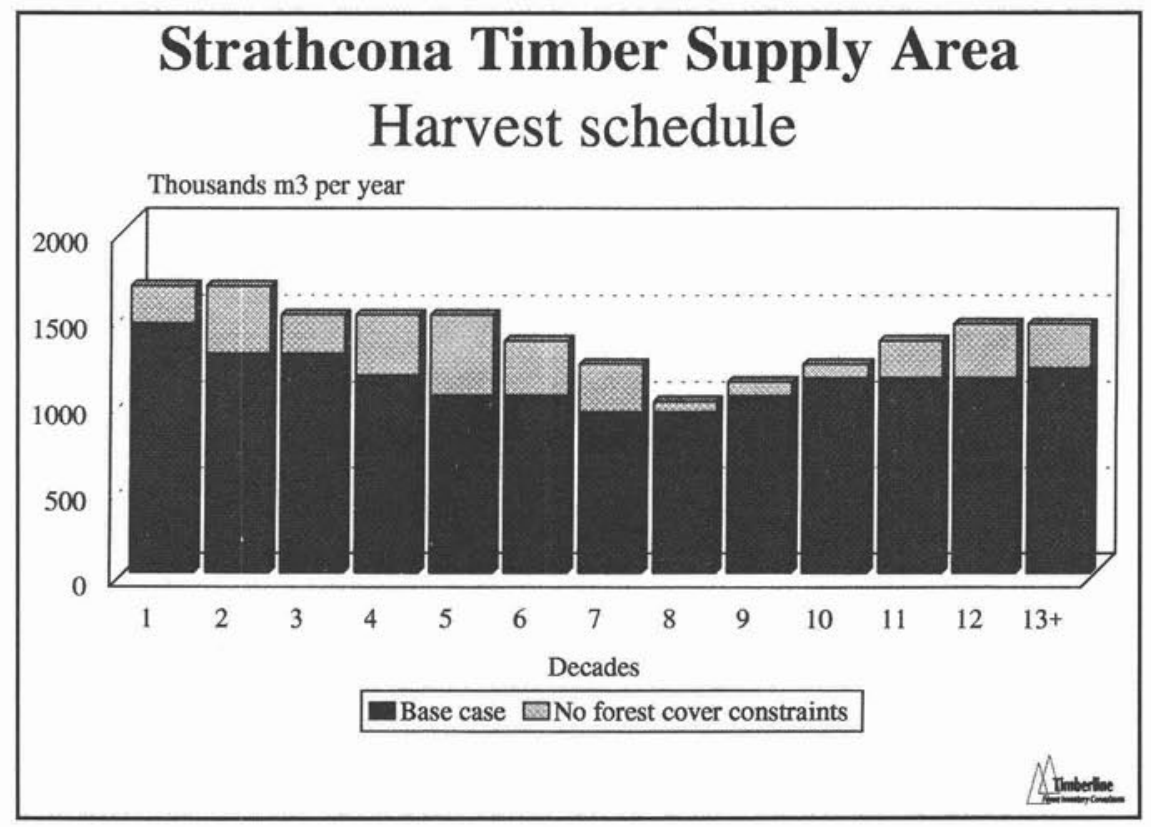

Figure 1. Comparison of harvests with and without forest cover constraints.

CASH-FM is a sequential forest inventory projection model. Its lineage includes WOSFOP (Hall 1977), Forman (Wang et al. 1987), PlanTS (Tanz et al. 1990), and the SQIRM and TIMSIM models developed by Timberline to be compatible with the BC MoF' model, FS-SIM. These models are primarily intended for use in forests managed under even-aged regimes.

\section{Pseudo-geography}

Cover constraints are implemented by accumulating harvest area in a disturbance class and qualifying area in a retention class, and then comparing these levels to the constraints. Most models implement constraints explicitly as maximum disturbance and minimum old growth retention, but in a non-spatial manner. There are spatial models available, but for these development plans must be created as input to the model. As a compromise, Timberline has developed CASH-FM utilizing pseudo-geographical concepts to achieve close adherence to the intent of forest cover constraints. Pseudo-geography is defined as the translation of spatial constraints into harvesting constraints based on geographic relationships.

In order to reduce the complexity of the forest description for the purpose of timber supply simulation, aggregation of individual forest stands is necessary. Biological similarity is captured by grouping stands into forest units on the basis of similar species and site productivity. CASH-FM shares this characteristic with most forest estate models. CASH-FM differs from other models in its approach to characterizing management differences by grouping stands into zones based on geographic proximity as well as management objectives. This pseudo-geographical approach is designed to capture the essence of spatial problems in a non-spatial context. CASH-FM does not directly address adjacency. It does though achieve a variable degree of spatial resolution depending on inventory formulation and management zone definition.

In their current implementation, forest cover constraints require a control area for application. Common sense indicates that the control area for a constraint set should correspond in some way to an element in the landscape. For example, the constraints asso- ciated with visual quality objectives are designed to operate on the scene visible from discrete viewpoints. The objective is to identify the "natural" constituency for forest cover constraints.

CASH-FM contains a hierarchical land base organization to assist in implementing control areas. Two levels of land units are used to define both geographically separate areas and areas of similar management regime. Forest cover constraints can be applied at both levels. A first or higher level grouping is the "watershed". A watershed, with no hydrological meaning implied, is a geographically contiguous area separated from other watersheds by some physical break. It can also be used to separate areas by tenure for cut control. This level is best used for constraints such as old growth retention. A second grouping level is the land unit or management zone. Management zones exist within watersheds and are control areas for the imposition of forest cover constraints for management of non-timber resources such as wildlife habitat.

\section{Implementation}

Implementation of the pseudo-geographic approach requires close co-operation among the timber supply analyst, the forest manager and the geographic information system analyst preparing the data. The land base must be segregated into zones which facilitate the application of management criteria. The number and size of zones and their definition can give considerable spatial resolution to the problem modeled. Pseudogeographic principles are used to visualize the intended control areas for forest cover constraints, and the zonal structure is built from there.

Pseudo-geographic principles are:

- All area within the forest estate will be retained for analysis

- Zones for the application of forest cover constraints will be contiguous

- Zones will reflect natural boundaries such as heights of land or waterways

- Area inside a zone is isolated from other zones

- Each discrete zone is an instance of harvest control policy. 


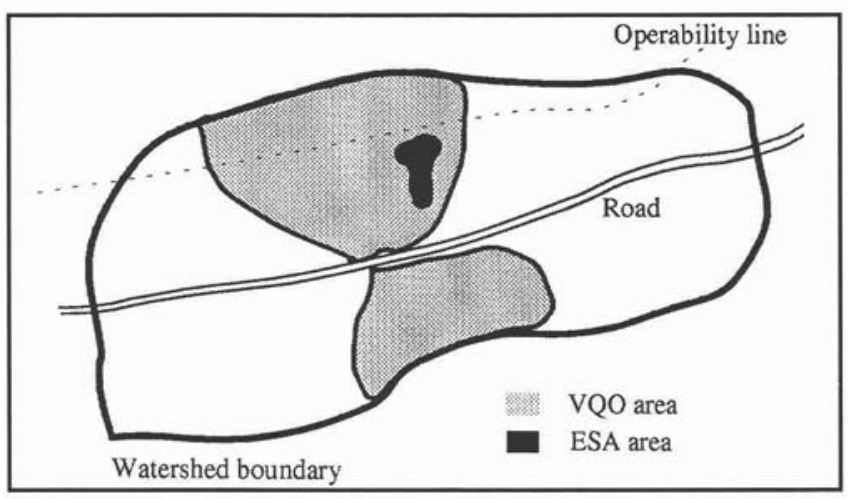

Figure 2. Non-spatial vs. pseudo-geographic analysis.

Zonation can serve three purposes:

- Defining control areas for the implementation of forest cover controls

- Identifying the location of harvest and silviculture, and implementing costs

- Providing a spatial component to descriptions of the state of the forest.

If none of these purposes are required then the basic land base organization can be used; every forest class belongs to a single land unit representing the entire area of a single watershed.

Using CASH-FM, all elements of the landscape are retained and appropriate portions are made available for various analysis options or for appropriate contributions to forest cover constraints. Forest classes (groups of stands) are assigned a scope which defines their eligibility for inclusion in constraints.

Forest classes may be non-contributing to harvest yet contributing to visual quality constraints, or perhaps contributing to harvest but unsuitable for thermal cover for wildlife. Other models can take these into account by modifying the values for cover constraints, but with CASH-FM the areas in the data set are included, marking them as contributing to analysis in different ways. With a properly defined and aggregated data set, this provides for the effect of spatial relationships.

Pseudo-geography improves our ability to model real world management through forest cover constraints. Figure 2 considers as an example a visual quality zone and how it is modelled in a non-spatial vs. a pseudo-geographic context.

In the non-spatial model, there would be one VQO zone, and elements of the zone are treated as one despite being discontiguous. Areas above the operability line and Environmentally Sensitive Areas (ESA) are green/inoperable areas and are considered in an aggregate manner by modifying the forest cover constraints with assumptions made on dispersion.

The pseudo-geographic approach would be to separate the VQO zone into its discrete portions, each affected only by the green/inoperable forest directly associated with it. All inoperable and ESA areas are available to the model, in order to contribute to forest cover constraints, but are not available for harvest. The inclusion of the inoperable area in the zone avoids the use of the green/operable ratio factor in modifying the forest cover constraint.

\section{Regular Case versus Hard Place}

Two approaches to modelling are available. The regular case is to determine through iterative analysis what the sustainable harvest schedule may be, given the current policies and limitations to harvesting. As an alternative, the "hard place analysis" involves modelling the harvest level required and demonstrating the forest characteristics which result over time.

The "hard place" analysis methodology was developed as a service to clients who feel themselves between the "rock" of mandated constraints and the "hard place" of economic survival. It is based on the premise that the effects on the forest or even the goals for management using forest cover constraints are usually not available. Using the "hard place" analysis to demonstrate acceptable forest structure through time could facilitate approval of the required harvest level.

\section{Conclusion}

Responding to a need to better reflect integrated resources management in timber supply analysis, the province of $\mathrm{BC}$ introduced forest cover constraints to its modelling approach. Timberline's CASH_FM extends this approach using pseudogeography to more closely achieve the intent of forest cover constraints for management of non-timber resources. This comes with the cost of increased complexity of the analytical process but improves the ability to identify the sustainable harvest based on society's requirements for non-timber resources.

\section{References}

BC Ministry of Forests Recreation Branch. 1991. Recreation Inventory Manual.

Hall, T.H. 1977. WOSFOP — Instruction Manual. NB Department of Natural Resources, Fredricton, NB. Unpublished.

BC Ministry of Forests Recreation Branch. 1993. Procedures for factoring recreation resources into timber supply analyses. Unpublished.

Tanz, J.S., A.F. Howard and R. Gasson. 1990. PLANTS User Manual, Version 1.0F. University of British Columbia, Vancouver, BC. Unpublished.

Timberline Forest Inventory Consultants. 1995a. Strathcona TSA Timber Supply Analysis. Unpublished.

Timberline Forest Inventory Consultants. 1995b. CASH-FM 4.0 Users Manual. Unpublished.

Wang, E.C., T.A. Erdle and T.G. Roussell. 1987. FORMAN wood supply model - User manual. NB Executive Forest Research Committee Inc., Fredricton, NB. Unpublished. 